\title{
Especiarias como antioxidantes naturais: aplicações em alimentos e implicação na saúde
}

\author{
DEL RÉ, P.V.; JORGE, N.* \\ Universidade Estadual Paulista - UNESP, Instituto de Biociências, Letras e Ciências Exatas, Departamento de \\ Engenharia e Tecnologia de Alimentos, Rua Cristóvão Colombo, 2265, Jardim Nazareth, CEP: 15054-000, São \\ José do Rio Preto-Brasil *njorge@ibilce.unesp.br
}

\begin{abstract}
RESUMO: O crescente interesse na substituição de antioxidantes sintéticos por naturais em alimentos tem fomentado a pesquisa sobre fontes vegetais, caracterização de matérias-primas e identificação de novos compostos antioxidantes. As reações de oxidação não são uma preocupação exclusiva das indústrias alimentícias, seu estudo é também amplamente necessário para evitar implicações indesejáveis na saúde humana. O objetivo desta revisão, depois de apresentar aspectos gerais sobre a oxidação, é concentrar-se nos benefícios da utilização das especiarias como antioxidantes naturais, em especial as da família Labiatae, amplamente utilizadas na culinária brasileira.
\end{abstract}

Palavras-chave: oxidação, antioxidantes naturais, especiarias

\begin{abstract}
Spices as natural antioxidants: their application in food and implication for health. The growing interest in replacing synthetic antioxidants by natural antioxidants in food has stimulated research on vegetable sources, raw material characterization and identification of new antioxidant compounds. Oxidation reactions are not an exclusive preoccupation of the food industry; studies regarding this issue are widely necessary in order to prevent undesired implications for human health. The aim of this review, after presenting overall aspects about oxidation, is to concentrate on the benefits of using spices as natural antioxidants, especially those from the Labiatae family, which are widely used in the Brazilian cuisine.
\end{abstract}

Key words: oxidation, natural antioxidants, spices

A oxidação lipídica que ocorre nos produtos alimentares é uma das principais preocupações em Tecnologia de Alimentos. É responsável por odores e sabores desagradáveis nos produtos, com consequente diminuição da segurança e qualidade nutricional, causados pela formação de compostos potencialmente tóxicos. A prevenção é economicamente importante e fundamental para a proteção da saúde humana (Tsai et al., 2005).

Os antioxidantes apresentam-se como uma alternativa para prevenir a deterioração oxidativa dos alimentos e minimizar os danos oxidativos nos seres vivos. Como o emprego de antioxidantes sintéticos na indústria de alimentos tem sido alvo de questionamentos quanto à inocuidade, demonstrando a possibilidade desses antioxidantes apresentarem alguma toxidez (Bauer et al., 2001), pesquisas encontram-se voltadas para a busca de compostos naturais que exibam esta propriedade funcional (Melo
\& Guerra, 2002).

A própria exigência do consumidor reforça 0 mercado potencial dos antioxidantes naturais, uma vez que existe grande desconforto de uma parcela da população em manter a aquisição e consumo de alimentos industrializados, cuja produção reconhecidamente envolva o emprego de substanciais quantidades de aditivos sintéticos (Valentão et al., 2002; Amarowicz et al., 2004).

O início do novo milênio, com o aumento da expectativa de vida e as crescentes informações divulgadas sobre saúde, levam o consumidor a procurar cada vez mais uma alimentação saudável para a prevenção das doenças. Paralelamente, os avanços da ciência permitem um melhor conhecimento sobre as propriedades dos alimentos.

Diversas ervas e especiarias culinárias já foram relatadas por possuírem atividades antioxidantes, sugerindo, inclusive, potencial benéfico à saúde

Recebido para publicação em 24/10/2010

Aceito para publicação em 02/04/2012

Rev. Bras. PI. Med., Botucatu, v.14, n.2, p.389-399, 2012. 
humana (Yanishlieva et al., 2006; Viuda-Martos et al., 2011).

Apesar das evidências bioquímicas, clínicas e epidemiológicas crescentes para muitos dos compostos funcionais, não existe ainda um consenso científico estabelecido que suporte decisões no âmbito de políticas mais globais de saúde pública referente ao seu uso. Há necessidade, então, de aprofundar o campo de pesquisa relativo a identificação destes compostos e seus mecanismos de ação biológica e a elaboração de alimentos dirigidos para as finalidades especiais de saúde.

Essas considerações apontam a importância do estudo das especiarias como antioxidantes naturais, de modo a minimizar os processos oxidativos e prevenir alterações metabólicas no organismo humano, tema que será objeto desta revisão.

\section{Oxidação e produção de radicais livres}

Oxidação lipídica é um fenômeno complexo induzido por oxigênio na presença de catalisadores, tais como calor, radicais livres, luz, pigmentos e íons metálicos (Laguerre et al., 2007). O mecanismo de oxidação pode ocorrer nos tecidos animais e vegetais e em produtos obtidos dos mesmos como óleos e gorduras.

Existem três formas pelas quais os óleos podem sofrer oxidação: autoxidação, fotoxidação e termoxidação (Berger \& Hamilton, 1995). Todas estas rotas contribuem para diminuir a qualidade e modificar a estrutura devido à degradação de vitaminas lipossolúveis e de ácidos graxos essenciais, além de afetar a integridade e segurança dos alimentos através da formação de compostos potencialmente tóxicos (Silva et al., 1999).

A autoxidação, reação complexa catalisada por fatores extrínsecos, se inicia com a formação de radicais livres e ocorre principalmente nos ácidos graxos insaturados, devido à instabilidade eletrônica que as duplas ligações apresentam tornando os hidrogênios ligados aos carbonos, onde as insaturações estão localizadas, mais fáceis de serem retirados da cadeia carbônica (Nawar, 1996; Salem-JR, 1999).

De acordo com Gordon (2001), a autoxidação de óleo ocorre por meio de processo em cadeia que envolve uma sequência de reações, desde a formação do radical livre em condições favorecidas por luz e calor (fase de iniciação), formação de peróxidos e hidroperóxidos (fase de propagação) e formação de produtos estáveis de oxidação, como aldeídos e cetonas (fase de terminação).

A fotoxidação é outro mecanismo proposto para a degradação oxidativa dos óleos, tendo em vista que a reação direta dos substratos lipídicos com o oxigênio atmosférico é termodinamicamente improvável de acontecer (Gordon, 1990). A reação é promovida essencialmente pela radiação UV em presença de sensibilizadores, envolvendo a participação do oxigênio singlete como intermediário reativo (Nawar, 1996).

Para simular o processo em que os óleos são submetidos a altas temperaturas e estudar os compostos originados durante o estresse térmico de óleos é muito comum a utilização da termoxidação. Método que consiste em submeter óleos e gorduras a elevadas temperaturas, porém sem a presença do alimento, ou seja, sem a umidade e demais componentes que provêm do alimento. Sendo assim, a temperatura e o oxigênio proveniente do ar são as principais variáveis que devem ser levadas em consideração. A oxidação de óleos na ausência de alimento também é utilizada para estudar a eficiência de antioxidantes contra a formação dos compostos degradativos, prejudiciais à saúde humana (Shyamala et al., 2005).

Os hidroperóxidos formados durante o processo de oxidação lipídica são essencialmente inodoros; contudo, eles se decompõem em uma grande variedade de compostos secundários voláteis e não-voláteis (Warner, 2002). Os compostos voláteis são parcialmente eliminados em processos de aquecimento do óleo e sua importância está relacionada com as características sensoriais (Jorge, 2004). Já os produtos de degradação não voláteis são de grande interesse sob o ponto de vista nutricional, já que fazem parte da dieta ao permanecerem dissolvidos no óleo e serem, portanto, incorporados aos alimentos (Warner, 2002).

Estudos revelam que alimentos alta ou moderadamente oxidados são bastante aterogênicos e que o colesterol oxidado parece ser particularmente, perigoso. Seus produtos de oxidação, denominados óxidos de colesterol, que compreendem um vasto número de compostos, promovem a aterosclerose, além de danos mutagênicos, citogênicos e arteriais (Adegoke et al., 1998).

Araújo (2004) afirma que os peróxidos afetam a atividade de diversas enzimas, alteram as lipoproteínas de baixa densidade (LDL) que estão envolvidas no desenvolvimento de lesões arterioscleróticas. Acredita-se que a oxidação das LDL seja a principal causa de doenças cardiovasculares e a decomposição de peróxidos formados pela ação da lipoxigenase pode ser o mecanismo inicial da oxidação da LDL.

Os hidroperóxidos e os produtos também podem reagir com proteínas, alterando o valor nutritivo, as propriedades reológicas e as características sensoriais dos alimentos. Os aminoácidos livres, principalmente a metionina, cistina, histidina, lisina e resíduos de outros aminoácidos sofrem substancial oxidação na presença de radicais livres (Jadhav et al., 1995). Como consequência, tem-se a diminuição da digestibilidade

Rev. Bras. PI. Med., Botucatu, v.14, n.2, p.389-399, 2012. 
e biodisponibilidade de aminoácidos essenciais, redução da solubilidade das proteínas e alteração na textura e cor dos alimentos (Kirk, 1984; Jadhav et al., 1995; Ferrari, 1998).

No organismo humano a oxidação de biomoléculas e produção de radicais livres são partes integrais do metabolismo. Os radicais livres são moléculas instáveis pelo fato de possuírem número ímpar de elétrons. Para atingir a estabilidade, estas moléculas necessitam adquirir elétrons e, portanto, reagem com a maioria dos compostos vizinhos, oxidando-os (Sanchez-Moreno, 2002).

As espécies reativas de oxigênio (ERO) e de nitrogênio (ERN) são continuamente produzidas no organismo e, em concentrações fisiológicas, desempenham funções essenciais relacionadas à sinalização do ciclo celular, à defesa imunológica (Ribeiro et al., 2005) e à biologia reprodutiva (Sanocka \& Kurpisz, 2004). Entretanto, em concentrações supra-fisiológicas e deficiência no sistema protetor, ocorre desequilíbrio entre agentes agressores e defensores, caracterizando o estresse oxidativo.

A geração de espécies reativas de oxigênio (EROs) é inevitável no metabolismo aeróbico do organismo. Este termo é frequentemente utilizado para descrever não somente radicais livres como o radical hidroxila ( $\left.{ }^{\circ} \mathrm{OH}\right)$, ânion radical superóxido $\left(\mathrm{O}_{2}{ }^{-}\right)$, óxido nítrico (NO') e radical peroxila (ROO'), mas também os que não são radicais livres como peróxido de hidrogênio $\left(\mathrm{H}_{2} \mathrm{O}_{2}\right)$, ozônio $\left(\mathrm{O}_{3}\right)$, oxigênio singlete $\left({ }^{1} \mathrm{O}_{2}\right)$ e ácido hipocloroso (HOCl), os quais podem induzir reações no organismo. Além dessas espécies serem geradas no processo endógeno fisiológico, também são geradas no patológico, e por fontes exógenas (Aruoma, 1994; Halliwell, 1994).

As fontes exógenas geradoras de radicais livres incluem tabaco, poluição do ar, solventes orgânicos, anestésicos, pesticidas e radiações (Kaur \& Kapoor, 2001; Soares, 2002). O excesso de exercícios, condições de vida e trabalho desgastantes também podem causar estresse oxidativo fisiológico (Ferrari, 1998).

Em sistemas biológicos, os ácidos graxos poli-insaturados das membranas são muito vulneráveis ao ataque de radicais livres, os quais desencadearão reações de oxidação nos ácidos graxos da membrana lipoprotéica, denominada peroxidação lipídica, que afetará a integridade estrutural e funcional da membrana celular, alterando sua fluidez e permeabilidade (Halliwell \& Aruoma, 1997).

Como resultado da peroxidação lipídica há destruição das membranas celulares, com alteração das bombas de $\mathrm{Na}^{+} / \mathrm{K}^{+}$(sódio/potássio) e $\mathrm{Ca}^{2+} / \mathrm{Mg}^{2+}$ (cálcio/magnésio), havendo perda da homeostase interna da célula por intenso desequilíbrio iônico, alteração do equilíbrio osmótico e consequente ruptura da membrana e morte celular (Olszewer et al., 1997).

Esse processo pode influenciar no aumento da viscosidade do sangue promovido por triglicérides e colesterol que interferem na transferência de oxigênio, nutrientes e substâncias essenciais para qualquer órgão do corpo (Halliwell \& Gutteridge, 1990). Os hidroperóxidos e os radicais lipídicos (alquila e peroxila) podem se decompor em uma série de produtos intermediários como o malonadialdeído e vários tipos de hidroxialquenais biologicamente ativos, tóxicos ou mutagênicos. Nesse caso, podem reagir com grupos funcionais de proteínas ou DNA, modificando estas macromoléculas (Burcham, 1998; Halliwell \& Gutteridge, 1990).

Esse quadro de desequilíbrio pode provocar modificações na função e na estrutura celular, causando, lenta e progressivamente, alterações nos tecidos e no código genético, e o desenvolvimento de vários problemas de saúde, dentre os quais destacamse vários tipos de neoplasias, aterosclerose, doenças neurodegenerativas, artrite, diabetes, danos à estrutura do DNA, processos inflamatórios com a redução do poder das células de defesa; e ainda existe uma relação com o processo de envelhecimento (Halliwell \& Gutteridge, 1990; Yen \& Chen, 1995; Pietta et al., 1998; Chow, 2002; Hsu \& Guo, 2002).

\section{Mecanismos de proteção}

Estruturalmente, os antioxidantes são compostos aromáticos que possuem pelo menos uma hidroxila, podendo ser sintéticos, largamente utilizados pela indústria de alimentos, ou naturais, como organosulfurados, fenólicos e terpenos, que fazem parte da constituição de diversos alimentos (Ramalho \& Jorge, 2006a).

Os antioxidantes podem ser classificados, segundo o mecanismo de ação, em primários ou secundários. Os antioxidantes primários atuam interrompendo a cadeia da reação através da doação de elétrons ou hidrogênio aos radicais livres (Adegoke et al., 1998), enquanto os antioxidantes secundários atuam na complexação com metais, sequestro de oxigênio, decomposição de hidroperóxidos para formar espécie não radical, absorção da radiação ultravioleta ou desativação de oxigênio singlete (Decker, 2002).

Bioquimicamente, o organismo humano possui sistemas de defesa para lidar com o estresse oxidativo, que incluem os sistemas enzimáticos, especialmente superóxido dismutase, glutationa peroxidase, catalase e glutationa (Laguerre et al., 2007). Auxiliando este sistema existe ainda a ação dos antioxidantes não enzimáticos, compostos principalmente pelas vitaminas, polifenóis, flavonóides, carotenoides e licopeno (Velioglu et al., 1998; Polyakov et al., 2001; Amarowicz et al., 2004). As 
ações destes compostos são de neutralizar radicais livres, quelar metais e bloquear a ação de espécies reativas, principalmente as de oxigênio.

Neste contexto, uma ampla definição de antioxidante é "qualquer substância que, presente em baixas concentrações, quando comparada a do substrato oxidável, atrasa ou inibe a oxidação deste substrato de maneira eficaz" (Ribeiro et al., 2008).

Os mecanismos endógenos de defesa podem ser auxiliados favoravelmente com a introdução de antioxidantes por meio da dieta (Brenna \& Pagliarini, 2001; Yildrim et al., 2001).

A dieta brasileira, característica de um país tropical, pode ser importante fonte de antioxidantes, pois é composta por vegetais e frutos que são ricos em vitaminas, compostos fenólicos e diversas substâncias que auxiliam a manter a saúde celular inibindo a instalação de patogenias ligadas ao estresse oxidativo.

A utilização de antioxidantes por meio da promoção de dieta adequada, ou seja, aquela que segue padrões estabelecidos de ingestão diária recomendada de nutrientes é preconizada por diversos especialistas. A ingestão de alimentos contendo antioxidantes, considerando-se a recomendação de consumo diário de 4 a 5 porções de hortaliças e 3 a 5 porções de frutas (Philippi et al., 1999), pode contribuir para que os indivíduos reduzam o risco de doenças crônico não-transmissíveis.

Evidências epidemiológicas mostram associação inversa entre o consumo freqüente de frutas e hortaliças e o risco de doenças crônicas nãotransmissíveis, como as cardiovasculares e diversos tipos de câncer (Yanishlieva \& Marinova, 2001; Higdon \& Frei, 2003; Kim et al., 2006) e também a diabetes (McCune \& Johns, 2002).

Embora possam ou não contribuir com o valor nutricional da dieta, as especiarias podem ser fontes de antioxidante natural relevante, visto que são utilizadas tradicionalmente como ingredientes, o que permite que sejam fácil e diretamente empregadas pelas propriedades antioxidantes em alimentos e possivelmente em outros sistemas (Lee \& Ahn, 2003).

\section{As especiarias}

O termo especiaria é definido como material seco da planta que normalmente é acrescentado ao alimento para melhorar o flavor (Madsen \& Bertelsen, 1995). Podem ser acrescentadas nos alimentos de várias formas, como inteiras, frescas, secas, como extratos isolados e/ou óleo essencial.

Os componentes provedores de sabores existentes nas especiarias consistem de compostos como alcoóis, ésteres, aldeídos, terpenos, fenóis, ácidos orgânicos e muitos outros elementos, que não têm sido totalmente identificados (Sagdiç, 2003).

A atividade antioxidante das especiarias está relacionada, principalmente, com a presença de compostos fenólicos. Compostos como os flavonóides e terpenóides (como timol, carvacrol e eugenol) também apresentam atividade antioxidante.

Quantitativamente, os compostos fenólicos são os antioxidantes mais representativos do reino vegetal, e podem ser quimicamente definidos como substâncias que possuem um anel aromático com uma ou mais hidroxilas; podem também apresentar outros grupos substituintes em sua estrutura, como ésteres, metil-ésteres e glicosídios (Martínez-Valverde et al., 2000). A Tabela 1 e a Figura 1 apresentam os principais compostos antioxidantes encontrados em especiarias.

Os compostos fenólicos exibem grande quantidade de propriedades fisiológicas como antialérgica, antiarteriogênica, antiinflamatória, antimicrobiana, antitrombótica, cardioprotetora e vasodilatadora, mas o principal efeito dos compostos fenólicos tem sido atribuído à ação antioxidante em alimentos (Balasundram et al., 2006).

Em geral os compostos fenólicos são multifuncionais como antioxidantes, pois atuam de várias formas: combatendo os radicais livres, quelando metais de transição, interrompendo a reação de propagação dos radicais livres na oxidação lipídica, modificando o potencial redox do meio, reparando a lesão das moléculas atacadas por radicais livres (Podsedek, 2007; Kyungmi \& Ebeler, 2008). Também bloqueiam a ação de enzimas específicas que

TABELA 1. Compostos antioxidantes identificados em especiarias selecionadas.

\begin{tabular}{|c|c|c|c|c|c|c|c|c|}
\hline \multirow{2}{*}{ Especiarias } & \multicolumn{3}{|c|}{ Diterpenos fenólicos } & \multicolumn{2}{|c|}{ Ácidos fenólicos } & \multicolumn{2}{|c|}{ Fenilpropanoides } & \multirow[b]{2}{*}{ Carvacro } \\
\hline & Rosmanol & Carnósico & Carnosol & Rosmarínico & Cafeico & Timol & Eugenol & \\
\hline Alecrim & $x$ & $x$ & $x$ & $x$ & & & & \\
\hline Manjericão & & & & & & $x$ & $x$ & $x$ \\
\hline Orégano & & & & $x$ & & $x$ & & $x$ \\
\hline Sálvia & & $x$ & $x$ & & $x$ & & & \\
\hline Tomilho & & & & & & $x$ & $x$ & $x$ \\
\hline
\end{tabular}

Fonte: Brewer, 2011.

Rev. Bras. PI. Med., Botucatu, v.14, n.2, p.389-399, 2012. 

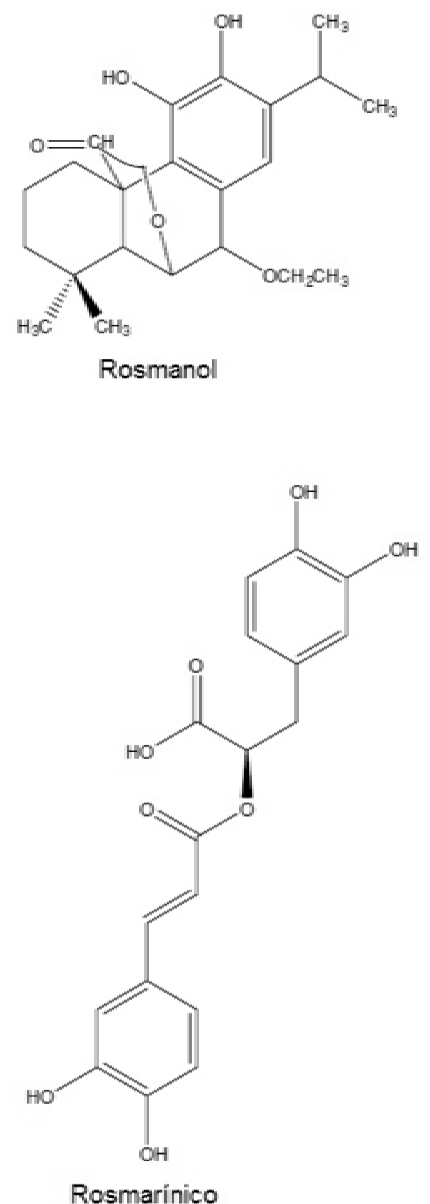
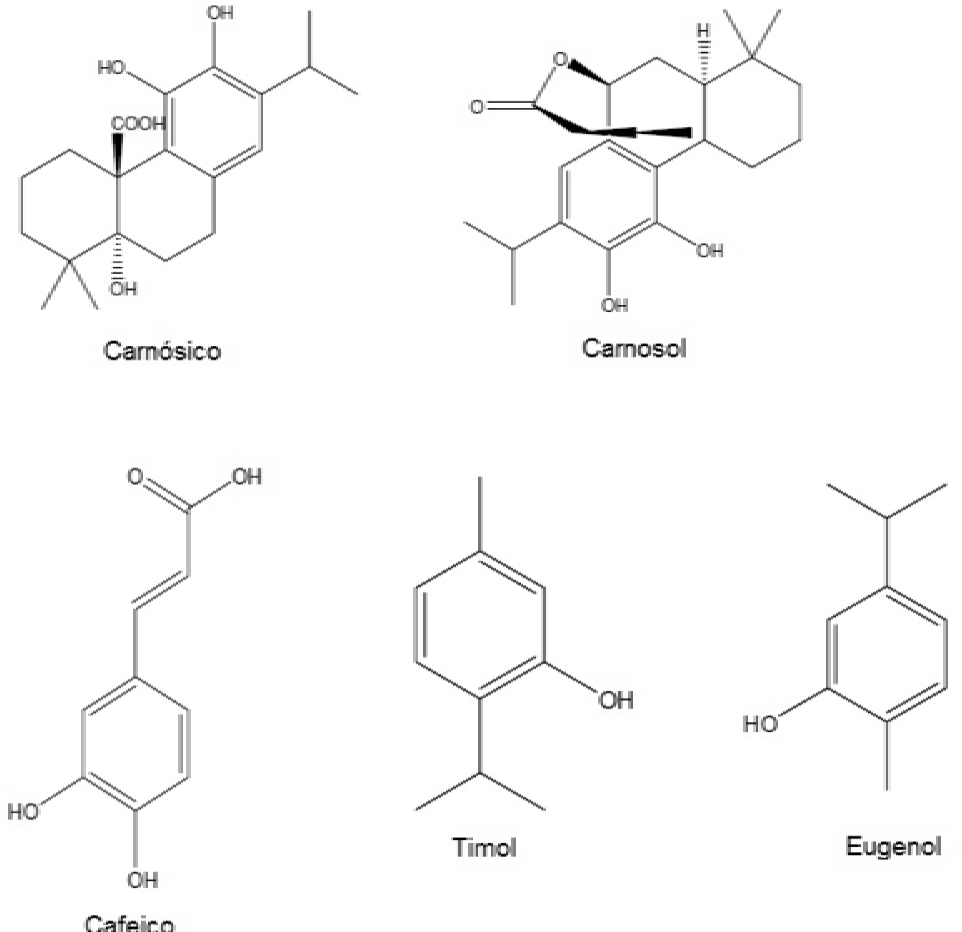

Eugenol

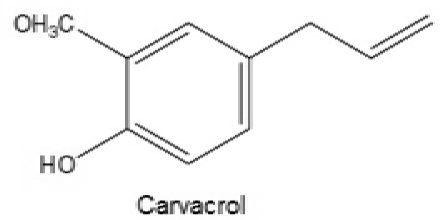

FIGURA 1. Estruturas dos principais antioxidantes naturais presentes em especiarias.

causam inflamação na biossíntese dos eicosanóides (Moreira \& Mancini-Filho, 2004); modificam as rotas metabólicas das prostaglandinas (Valko et al., 2007); protegem a aglomeração plaquetária e inibem a ativação de carcinógenos (Liu, 2005).

Outro fator de destaque das especiarias é no processo digestivo. A presença de enzimas é fundamental para a digestão de nutrientes, acreditase que alguns extratos vegetais possam estimular a produção de saliva e dos sucos gástrico e pancreático, favorecendo a secreção enzimática e melhorando a digestibilidade dos nutrientes (Mellor, 2000).

Entretanto, para uma especiaria atuar como moduladora da promoção da saúde, não depende só dos teores de fitoquímicos, mas também da forma de preparo e da quantidade consumida.

Similarmente ao que ocorre com outras plantas, a composição e concentração de princípios ativos dos extratos de especiarias podem apresentar grandes diferenças segundo a origem, espécie, variedade, controle genético, fase de desenvolvimento durante a colheita, estímulos proporcionados pelo meio como, por exemplo, fatores climáticos, exposição a microrganismos, insetos e outros herbívoros, poluentes e tipo de processamento póscolheita. Todas estas características fornecem propriedades sensoriais específicas, de maneira particular a cada planta aromática, podendo determinar em algumas espécies a concentração de determinado princípio ativo, o que dificulta generalizar os resultados referentes à composição destes tipos de materiais (Troncoso et al., 2005).

Observa-se um interesse crescente da população e de pesquisadores da área da saúde em buscar estratégias alimentares preventivas e conhecimentos sobre os efeitos funcionais dos antioxidantes naturais, com destaque para as plantas aromáticas. As ervas e especiarias são uma das principais fontes de antioxidantes naturais na dieta humana, principalmente as especiarias da família Labiatae (Pokorny, 2007).

A família Labiatae compreende 150 gêneros com aproximadamente 3.500 espécies, nativas principalmente do Mediterrâneo, embora algumas tenham origem na Austrália, Sudoeste da Ásia e América do Sul (Justo et al., 2008). As principais 
espécies consumidas no Brasil desta família são o alecrim, o manjericão, o orégano, a sálvia e o tomilho.

\section{Alecrim (Rosmarinus officinalis L.)}

O nome Rosmarinus vem do latim e significa "orvalho que vem do mar", isso por causa das flores azuladas, pertencentes à planta, que inundam as praias do Mediterrâneo, lembrando o orvalho. Originário da Europa, o alecrim é adaptável a solos secos, pobres e bem drenados; em relação ao clima, adaptase melhor ao subtropical (Alonso, 1998).

Dentre as ervas da família Labiatae, o alecrim é o mais extensivamente estudado e seus extratos são os mais conhecidos como antioxidantes naturais. A atividade antioxidante dos extratos de alecrim é atribuída principalmente à presença de compostos fenólicos, voláteis e não voláteis, como os flavonóides, os ácidos fenólicos e os diterpenos fenólicos, tais como o ácido carnósico e o carnosol (hidrofóbicos) e o ácido rosmarínico e o rosmanol (hidrofílicos), sendo que mais de $90 \%$ desta atividade é atribuída aos compostos hidrofóbicos, principalmente ao ácido carnósico. Contudo, este ácido é bastante instável e sua degradação leva à formação de carnosol (metil éster do ácido carnósico), que se degrada, por sua vez, em rosmanol, epirosmanol e 7-metilrosmanol (Justo et al., 2008).

Os extratos de antioxidantes comerciais do alecrim estão disponíveis como um pó fino. Dependendo da quantidade de atividade dos antioxidantes, eles são recomendados para o uso nas concentrações entre 200 e $1.000 \mathrm{mg} \mathrm{kg}^{-1}$ do produto processado (Shahidi et al., 1992).

O alecrim tem demonstrado um ótimo potencial antioxidante em diversos estudos que visam a aplicação desta especiaria em diversos produtos que são susceptíveis à oxidação, tais como maioneses, salsichas e diferentes tipos de carnes (Carvalho-Junior et al., 2005; Lee et al., 2005a; Estévez \& Cava, 2006).

Ramalho \& Jorge (2006b) avaliaram a atividade antioxidante do extrato de alecrim em comparação com o $\alpha$-tocoferol, utilizando óleo de soja purificado como substrato lipídico e, apesar do $\alpha$-tocoferol ser mais eficiente, a concentração de $1.000 \mathrm{mg} \mathrm{kg}^{-1}$ de extrato de alecrim mostrou efeito positivo sobre a estabilidade oxidativa, medida por Rancimat, e poderia ser indicado como antioxidante alternativo na conservação de óleos.

Pesquisadores (Genena et al., 2008) confirmaram a ação antioxidante, antibacteriana e antifúngica de extratos de alecrim obtidos com dióxido de carbono supercrítico, demonstrando ser produto promissor no que diz respeito à incorporação em alimentos, cosméticos e produtos farmacêuticos.

Manjericão (Ocimum basilicum L.)

A família Lamiaceae possui cerca de 200 gêneros e aproximadamente 3.500 espécies. Entre as espécies de maior importância econômica destacam-se o manjericão (Ocimum basilicum L.), também denominado de alfavaca, alfavaca-cheirosa, basílico ou manjericão comum, é a espécie mais intensamente cultivada. Esta especiaria foi amplamente plantada após a vinda de imigrantes italianos para o Brasil, sendo utilizada como folhas verdes em massas, condimento in natura e processada como folhas secas inteiras ou moídas e, ainda, como matéria-prima para a indústria de óleos essenciais (Javanmardi et al., 2003; Hussain et al., 2008).

O manjericão pode ser considerado cultura anual ou perene, conforme o local de cultivo. De acordo com o aroma pode ser classificado em doce, limão, cinamato ou canela, cânfora, anis e cravo. Existem diversas finalidades para uso na culinária, como planta ornamental, medicinal e aromática, sendo o óleo essencial valorizado no mercado internacional pelo teor de linalol (Blank et al., 2004).

Tem sido amplamente estudado pelo uso histórico e presença de compostos fenólicos (Makri \& Kintzios, 2008). É também uma fonte de aromas e óleos essenciais que contém compostos biologicamente ativos com propriedades antimicrobianas (Wannissorn et al., 2005; Gutierrez et al., 2008; Hussain et al., 2008).

Lee \& Scagel (2009) caracterizaram o conteúdo de compostos fenólicos do manjericão e identificaram a presença de ácido chicórico e ácido caftárico, conhecidos pelos efeitos imunoestimulantes, assim como pelas propriedades antioxidantes.

Compostos presentes nos extratos de manjericão e tomilho, em particular eugenol, timol e carvacrol são capazes de inibir a oxidação, comparável aos antioxidantes conhecidos, BHT e $\alpha$-tocoferol. Além disso, a ingestão desses compostos aromáticos pode ajudar a prevenir danos oxidativos in vivo, como a peroxidação lipídica, que é associada ao câncer, envelhecimento precoce, aterosclerose e diabetes (Lee et al., 2005b).

Politeo et al. (2007) analisaram a composição química e a capacidade antioxidante de agliconas do manjericão comparadas ao óleo essencial. A comparação da composição química de agliconas voláteis com a composição química do óleo essencial revelou quatro compostos comuns, o eugenol, chavicol, linalol e $\alpha$-terpineol, com grande potencial antioxidante.

Beriæ et al. (2008) avaliaram o efeito protetor do manjericão contra danos oxidativos do DNA e mutagêneses. Em todos os testes, o efeito antimutagênico dos derivados de manjericão foi comparável com o modelo antioxidante da vitamina $\mathrm{E}$, fator atribuído principalmente às propriedades antioxidantes.

Foi demonstrado que os extratos de manjericão retardam a oxidação de óleo de girassol. A efetividade dos extratos foi estimada com base no período de indução, determinado por curva cinética

Rev. Bras. PI. Med., Botucatu, v.14, n.2, p.389-399, 2012. 
durante a oxidação do óleo de girassol a $100^{\circ} \mathrm{C}$ (Marinova \& Yanishlieva, 1997).

Gülçin et al. (2007) determinaram a atividade antioxidante e a capacidade de sequestrar radicais livres dos extratos etanólico e aquoso de manjericão por diferentes métodos in vitro, dentre eles o método do tiocianato férrico. Os extratos etanólico e aquoso, na concentração de $50 \mathrm{mg} \mathrm{mL}^{-1}$ apresentaram $94,8 \mathrm{e}$ $97,5 \%$ de inibição da oxidação lipídica, respectivamente. Juntachote \& Berghofer (2005) ao estudarem os extratos etanólicos de duas espécies diferentes de manjericão, verificaram que o do tipo Ocimum sanctum L. apresentou maiores propriedades antioxidantes do que do tipo Alpinia galanga, presumivelmente devido às diferenças na estrutura dos componentes antioxidantes. Entretanto, ambos os extratos etanólicos podem ser usados como antioxidantes de alimentos naturais em uma possível substituição aos antioxidantes sintéticos, pois além das propriedades naturais, eles têm a vantagem de serem de fácil obtenção e baixo custo.

\section{Orégano (Origanum vulgare L.)}

O gênero Origanum é uma erva perene na forma de arbusto e nativa das regiões Euro-Siberiana e Irano-Siberiana, sendo atualmente reconhecidas 38 espécies deste gênero difundidas no mundo (Aligiannis et al., 2001). Devido a ampla variedade de características químicas e de aroma, diferentes espécies e tipos de Origanum são amplamente utilizados como erva culinária, flavorizante de alimentos, em bebidas alcoólicas e em perfumaria na obtenção e fragrâncias picantes (Novak et al., 2000; Aligiannis et al., 2001).

O orégano tem ganhado o interesse de muitos grupos de pesquisa como um potente antioxidante para sistemas lipídicos. A espécie se destaca pela ação antioxidante. As folhas secas bem como o óleo essencial do orégano têm sido usados medicinalmente por vários séculos em diferentes partes do mundo e, 0 efeito positivo sobre a saúde humana tem sido atribuído tanto ao óleo essencial como frações solúveis de fenólicos (Cervato et al., 2000).

Kikuzaki \& Nakatani (1989) isolaram cinco diferentes compostos fenólicos do extrato metanólico de folhas de orégano e entre estes o ácido rosmarínico foi encontrado em concentrações mais elevadas. O ácido rosmarínico além de possuir propriedades antioxidantes como bloqueador de espécies reativas e inibidor da peroxidação lipídica (Kosar et al., 2008), Ihe tem sido atribuídas diversas atividades biológicas, como antidepressivos (Takeda et al., 2002), hepatoprotetor (Osakabe et al., 2002), antiinflamatório (Osakabe et al., 2004) e antitumorais (McKay \& Blumberg, 2006).

Segundo Cervato et al. (2000), extratos de orégano (aquoso e metanólico) provaram ser eficazes em quantidades mínimas ( 0,1 a 1 mg de folhas secas), quantidade menor do que normalmente utilizados na dieta. A pesquisa demonstrou que extratos de orégano são eficazes na prevenção de todas as fases do processo oxidativo, primeiro através da neutralização dos radicais livres, depois pelo bloqueio de peroxidação catalisada pelo ferro (e presumivelmente por outros metais de transição) e, finalmente, pela interrupção do radical lipídico na cadeia de reações. De igual importância foi o efeito anti-glicosilação, essencial para a preservação e eficácia das proteínas do plasma. O fato de que existem vários mecanismos antioxidantes torna o orégano bloqueador particularmente eficaz de uma série de eventos próoxidantes.

Chun et al. (2005) correlacionaram a alta efetividade antimicrobiana de extrato de orégano contra úlcera associada ao Helicobacter pylori à alta atividade antioxidante, correspondente as grandes quantidades de compostos fenólicos.

Entre as alternativas de aditivos fitogênicos, o extrato de orégano se destaca, visto que possui dois dos principais fenóis com propriedades antimicrobianas, o carvacrol e o timol, que agem sobre a membrana celular bacteriana, impedindo a divisão mitótica, causando desidratação nas células e impedindo a sobrevivência de bactérias patogênicas (Fukayama et al., 2005).

\section{Sálvia (Salvia officinalis L.)}

É originária do sul da Europa. A planta é um arbusto pequeno, lenhoso de 30 a $50 \mathrm{~cm}$ de altura, aromático; folhas alongadas e arredondadas nos caules, que são recobertos por películas finas e macias; flores azul-violáceas, formando cachos. Possui sabor amargo e odor forte, o óleo essencial contém cineol, cânfora, borneol, tujona e outros terpenos. Contém ainda ácido ursólico e taninos (Martins et al., 2002).

Existem cerca de 1.000 espécies de sálvia que têm sido utilizadas de muitas formas, dentre elas destacas-se a Salvia officinalis pela ação antioxidante. O principal composto responsável pela atividade antioxidante na sálvia é o ácido caféico, os outros componentes ativos, especialmente na variedade $S$. officinalis, são os diterpenos, o ácido carnósico e derivados carnosol (Kosar et al., 2008).

Segundo Ulubelen (2003), uma série de diterpenos já foi obtida de espécies de sálvia e suas estruturas e atividades biológicas testadas, com destaque para atividades cardiovasculares e antibacterianas.

Há também pesquisas que têm demonstrado que o óleo essencial de sálvia pode melhorar a memória e tem se mostrado promissor no tratamento da doença de Alzheimer (Perry et al., 1999; 2003). Jung et al. (2009) avaliaram o extrato etanólico

Rev. Bras. PI. Med., Botucatu, v.14, n.2, p.389-399, 2012. 
de sálvia e confirmaram, além de atividade antioxidante, eficácia terapêutica por ação antiinflamatória confirmada tanto in vitro como in vivo, podendo proporcionar uma base farmacológica para o tratamento de doenças inflamatórias e tumores.

\section{Tomilho (Thymus vulgaris L.)}

Tomilho, planta originária da Europa, das regiões em torno do Mediterrâneo, tem haste lenhosa na base e herbácea na ponta, cujos ramos são eretos, aveludados e de cor branca, folhas verdeacinzentadas e pontilhadas na face superior e flores róseas ou brancas (Martins et al., 2002). Originalmente é muito empregado como erva medicinal, mas tem sido comumente utilizado como uma especiaria culinária para adicionar sabor (Yanishlieva et al., 2006; El-Nekeety et al., 2011).

Assim como no orégano, os compostos fenólicos, timol e carvacrol, são os principais compostos dos extratos de tomilho. A extremidade hidrofóbica destes componentes interage com a membrana celular das bactérias, alterando sua permeabilidade para cátions como hidrogênio $\left(\mathrm{H}^{+}\right)$e potássio $\left(\mathrm{K}^{+}\right)$. O descontrole no gradiente de íons leva as células bacterianas à morte (Lambert et al., 2001).

Além de propriedades antimicrobianas, 0 tomilho é também conhecido com anti-séptico e expectorante (Baranauskiene et al., 2003) e atua na inibição da peroxidação lipídica (Nguyen et al., 2000).

Segundo Teissedre \& Waterhouse (2000), o óleo essencial de tomilho, abundante em timol, carvacrol, cuminol e eugenol, apresentou inibição moderada de oxidação da LDL (20-27\%).

Os extratos de tomilho apresentam potente atividade antioxidante, seu efeito inibitório foi avaliado por Lee \& Shibamoto (2002) em concentrações de $10 \mathrm{mg} \mathrm{mL}^{-1}$, a qual foi comparável a ação do BHT e $\alpha$ tocoferol em concentrações variando de 10 a $500 \mathrm{mg}$ $\mathrm{mL}^{-1}$.

\section{CONSIDERAÇÕES FINAIS}

Considerando a preocupação atual com efeitos adversos que os antioxidantes sintéticos podem causar ao organismo, observa-se que os extratos de especiarias podem apresentar-se como fonte acessível de antioxidantes naturais. A adição de especiarias, de diferentes tipos e formas, pode evitar a deterioração oxidativa em vários sistemas, além de possível suplemento alimentício e farmacêutico.

Evidências demonstram que novos antioxidantes podem ser incorporados dentro do arsenal terapêutico, indicando que as pesquisas envolvendo agentes antioxidantes naturais devem continuar, pois as mesmas se mostram de suma importância para a saúde humana.

\section{AGRADECIMENTO}

À FAPESP - Fundação de Amparo à Pesquisa do Estado de São Paulo (processo n. 07/ 50341-8), pelo auxílio à pesquisa e ao CNPq Conselho Nacional de Desenvolvimento Científico e Tecnológico, pela bolsa de produtividade em pesquisa.

\section{REFERÊNCIA}

ADEGOKE, G.O. et al. Antioxidants and lipid oxidation in food - a critical appraisal. Journal of Food Science \& Technology, v.35, n.4, p.283-98, 1998.

ALIGIANNIS, N. et al. Composition and antimicrobial activity of the essential oil of two Origanum species. Journal of Agricultural and Food Chemistry, v.49, n.9, p.4168-70, 2001.

ALONSO, J.R. Tratado de fitomedicina: bases clínicas y farmacológicas. Buenos Aires: Isis Ediciones SRL, 1998. 987p.

AMAROWICZ, R.A. et al. Free-radical scavenging capacity and antioxidant activity of selected plant species from the Canadian prairies. Food Chemistry, v.84, n.4, p.55162, 2004.

ARAÚJO, J.M.A. Química de alimentos: teoria e prática. 3.ed. Viçosa: Editora UFV, 2004. 480p.

ARUOMA, O.I. Nutrition and healt aspects of free radicals and antioxidants. Food and Chemical Toxicology, v.32, n.7, p.671-83, 1994.

BALASUNDRAM, N.; SUNDRAM, K.; SAMMAN, S. Phenolic compounds in plants and agri-industrial byproducts: antioxidant activity, occurrence, and potential uses. Food Chemistry, v.99, n.1, p.191-203, 2006.

BARANAUSKIENE, P.R. et al. Influence of nitrogen fertilizers on the yield and composition of thyme (Thymus vulgaris). Journal of Agricultural and Food Chemistry, v.51, n.26, p.7751-8, 2003.

BAUER, A.K. et al. The lung tumor promoter, butylated hydroxytoluene (BHT), causes chronic inflammation in promotion-sensitive BALB/cByJ mice but not in promotion-resistant CXB4 mice. Toxicology, v.169, n.1, p.1-15, 2001.

BERIÆE, T. et al. Protective effect of basil (Ocimum basilicum L.) against oxidative DNA damage and mutagenesis. Food and Chemical Toxicology, v.46, n.2, p.724-32, 2008.

BERGER, K.G.; HAMILTON, R.J. Lipids and oxygen: is rancidity avoidable in practive? In: HAMILTON, R.J. Developments in oils and fats. London: Chapman \& Hall, 1995. p.192-204.

BLANK, A.F. et al. Caracterização morfológica e agronômica de acessos de manjericão e alfavaca. Horticultura Brasileira, v.22, n.1, p.113-6, 2004.

BRENNA, O.V.; PAGLIARINI, E. Multivariate analysis of antioxidant power and polyphenolic composition in red wines. Journal of Agricultural and Food Chemistry, v.49, n.10, p.4841-4, 2001.

BREWER, M.S. Natural antioxidants: sources, compounds, mechanisms of action, and potential applications. Comprehensive Reviews in Food Science and Food Safety, v.10, p.221-47, 2011. 
BURCHAM, P.C. Genotoxic lipid peroxidation products: their DNA damaging proporties and role in the formation of endogenous DNA addutcts. Mutagenesis, v.13, n.3, p.287-305, 1998.

CARVALHO-JUNIOR, R.N. et al. Supercritical fluid extraction from rosemary (Rosmarinus officinalis): kinetic data, extract's global yield, composition, and antioxidant activity. The Journal of Supercritical Fluids, v.35, n.3, p.197-204, 2005.

CERVATO, C. et al. Antioxidant properties of oregano [Origanum vulgare] leaf extracts. Journal of Food Biochemistry, v.24, n.6, p.453-65, 2000.

$\mathrm{CHOW}, \mathrm{C.K}$. Antioxidant nutrients and environmental healh: introduction. Toxicology, v.180, n.1, p.1-3, 2002.

CHUN, S.S. et al. Phenolic antioxidants from clonal oregano (Origanum vulgare) with antimicrobial activity against Helicobacter pylori. Process Biochemistry, v.40, n.2, p.809-16, 2005.

DECKER, E.A. Antioxidant mechanisms. In: AKOH, C.C.; MIN, D.B. Food lipids: chemistry, nutrition and biotechnology. 2.ed. New York: Marcel Dekker, 2002. p.517-42.

EL-NEKEETY, A.A. et al. Antioxidant properties of Thymus vulgaris oil against aflatoxin-induce oxidative stress in male rats. Toxicon, v.57, n.7-8, p.984-91, 2011.

ESTÉVEZ, M.; CAVA, R. Effectiveness of rosemary essential oil as an inhibitor of lipid and protein oxidation: contradictory effects in different types of frankfurters. Meat Science, v.72, n.2, p.348-55, 2006.

FERRARI, C.K.B. Oxidação lipídica em alimentos e sistemas biológicos: mecanismos gerais e implicações nutricionais e patológicas. Revista de Nutrição, v.11, n.1, p.3-14, 1998.

FUKAYAMA, E.H. et al. Extrato de orégano como aditivo em rações para frangos de corte. Revista Brasileira de Zootecnia, v.34, n.6, p.2316-26, 2005.

GENENA, A.K. et al. Rosemary (Rosmarinus officinalis) a study of the composition, antioxidant and antimicrobial activities of extracts obtained with supercritical carbon dioxide. Ciência e Tecnologia de Alimentos, v.28, n.2, p.463-9, 2008.

GORDON, M.H. The mechanism of antioxidant action in vitro. In: HUDSON, B.J.F. (Ed.). Food antioxidants. London: Elsevier Applied Science, 1990. p.1-18.

GORDON, M.H. The development of oxidative rancidity in foods. In: POKORNY, J.; YANISHLIEVA, N.; GORDON, M. (Ed.). Antioxidants in food: practical applications. Cambridge: Woodhead Publishing, 2001. p.7-21.

GÜLÇIN, I.; ELMASTAS, M.; ABOUL-ENEIN, H.Y. Determination of antioxidant and radical scavenging activity of basil (Ocimum basilicum L. family Lamiaceae) assayed by different methodologies. Phytotherapy Research, v.21, n.4, p.354-61, 2007.

GUTIERREZ, J., BARRY-RYAN, C., BOURKE, P. The antimicrobial efficacy of plant essential oil combinations and interactions with food ingredients. International Journal of Food Microbiology, v.124, n.1, p.91-7, 2008. HALLIWELL, B.; ARUOMA, O.I. Free radicals and antioxidants: the need for in vivo markers of oxidative stress. In: ARUOMA, O.I.; CUPPETT, S.L. (Ed.) Antioxidant methodology in vivo and in vitro concepts. Illinois: AOCS Press, 1997. p.1-22.

HALLIWELL, B. Free radicals and antioxidants: a personal view. Nutrition Reviews, v.52, n.8, p.253-65, 1994.

HALLIWELL, B.; GUTTERIDGE, J.M.C. Free radicals in biology and medicine. Oxford: Clarendon Press, 1990. 543p.

HIGDON, J.V.; FREI, B. Tea catechins and polyphenols: health effects, metabolism, and antioxidant functions. Critical Reviews in Food Science and Nutrition, v.43, n.1, p.89-143, 2003.

HSU, P.C.; GUO, Y.L. Antioxidant nutrients and lead toxicity. Toxicology, v.180, n.1, p.33-44, 2002.

HUSSAIN, A.I. et al. Chemical composition, antioxidant and antimicrobial activities of basil (Ocimum basilicum) essential oils depends on seasonal variations. Food Chemistry, v.108, n.3, p.986-95, 2008.

JADHAV, S.J. et al. Lipid oxidation in biological and foods systems. In: MADHAVI, D.L.; DESHPANDE, S.S.; SALUNKHE, D.K. (Ed.). Food antioxidants: technological, toxicological and health perspectives. New York: Marcel Dekker, 1995. p.5-62.

JAVANMARDI, J. et al. Antioxidant activity and total phenolic content of Iranian Ocimum accessions. Food Chemistry, v.83, p.547-50, 2003.

JORGE, N. Alterações químicas em óleos e gorduras de fritura. Nutrição Brasil, v.3, n.4, p.247-53, 2004.

JUNG, H.J. et al. Anti-inflammatory, anti-angiogenic and anti-nociceptive activities of an ethanol extract of Salvia plebeia R. Brown. Journal of Ethnopharmacology, v.126, n.2, p.355-60, 2009.

JUNTACHOTE, T.; BERGHOFER, E. Antioxidative properties and stability of ethanolic extracts of Holy basil and Galangal. Food Chemistry, v.92, n.2, p.193-202, 2005.

JUSTO, O.R. et al. Avaliação do potencial antioxidante de extratos ativos de plantas obtidos por extração com fluido supercrítico. Química Nova, v.31, n.7, p.1699-705, 2008.

KAUR, C.; KAPOOR, H.C. Antioxidants in fruits and vegetables - the millennium's health. Journal of Food Science and Technology, v.36, n.8, p.703-25, 2001.

KIKUZAKI, H.; NAKATANI, N. Structure of a new antioxidative phenolic acid from oregano (Oreganum vulgare L.). Agricultural and Biological Chemistry, v.53, n.2, p.519-24, 1989.

$\mathrm{KIM}, \mathrm{K} . \mathrm{N}$. et al. Retinoic acid and ascorbic acid act synergistically in inhibiting human breast cancer cell proliferation. The Journal of Nutritional Biochemistry, v.17, n.7, p.454-62, 2006.

KIRK, J.R. Biological availability of nutrients in processed food. Journal of Chemical Education, v.61, n.4, p.364-7, 1984.

KOSAR, M.; GÖGER, F.; BASER, K.H.C. In vitro antioxidant properties and phenolic composition of Salvia virgata Jacq. from Turkey. Journal of Agricultural and Food Chemistry, v.56, n.7, p.2369-74, 2008.

KYUNGMI, M.; EBELER, S.E. Flavonoid effects on DNA oxidation at low concentrations relevant to physiological levels. Food and Chemical Toxicology, v.46, n.1, p.96104, 2008.

LAGUERRE, M.; LECOMTE, J.; VILLENEUVE, P. Evaluation of the ability of antioxidants to counteract lipid oxidation: existing methods, new trends and challenges. Progress in Lipid Research, v.46, n.5, p.244-82, 2007. 
LAMBERT, R.J.W. et al. A study of the minimum inhibitory concentration and mode of action of oregano essential oil, thymol and carvacrol. Journal of Applied Microbiology, v.91, n.3, p.453-62, 2001.

LEE, E.J.; AHN, D.U. Production of volatiles from fatty acids and oils by irradiation. Journal of Food Science, v.68, n.1, p.70-5, 2003.

LEE, J.W. et al. Combined effects of gamma irradiation and rosemary extract on the shelf-life of a ready-to-eat hamburger steak. Radiation Physics and Chemistry, v.72, n.1, p.49-56, $2005 a$.

LEE, S.J. et al. Identification of volatile components in basil (Ocimum basilicum L.) and thyme leaves (Thymus vulgaris L.) and their antioxidant properties. Food Chemistry, v.91, n.1, p.131-7, 2005b.

LEE, J.; SCAGEL, C.F. Chicoric acid found in basil (Ocimum basilicum L.) leaves. Food Chemistry, v.115, n.2, p.650-6, 2009.

LEE, K.G.; SHIBAMOTO, T. Determination of antioxidant potential of volatile extracts isolated from various herbs and spices. Journal of Agricultural and Food Chemistry, v.50, n.17, p.4947-52, 2002.

LIU, F. Antioxidant activity of garlic acid from rose flowers in senescence accelerated mice. Life Sciences, v.77, n.3, p.230-40, 2005.

MADSEN, H.L.; BERTELSEN, G. Spices as antioxidants. Trends in Food Science and Technology, v.6, n.8, p.2717, 1995.

MAKRI, O.; KINTZIOS, S. Ocimum sp. (basil): botany, cultivation, pharmaceutical properties, and biotechnology. Journal of Herbs Spices and Medicinal Plants, v.13, n.3, p.123-50, 2008.

MARINOVA, E.M.; YANISHLIEVA, N.V. Antioxidative activity of extracts from selected species of the family Lamiaceae in sunflower oil. Food Chemistry, v.58, n.3, p.245-8, 1997. MARTíNEZ-VALVERDE, I.; PERIAGO, M.J.; ROS, G. Significado nutricional de los compuestos fenólicos de la dieta. Archivos Latinoamericanos de Nutricion, v.50, n.1, p.5-18, 2000.

MARTINS, E.R. et al. Plantas medicinais. 4 ed. Viçosa: Editora UFV, 2002. 220p.

McCUNE, L.M.; JOHNS, T. Antioxidant activity in medicinal plants associated with the symptoms of diabetes mellitus used by the indigenous peoples of the North American boreal forest. Journal of Ethnopharmacology, v.82, n.23, p.197-205, 2002.

McKAY, D.L.; BLUMBERG, J.B. A review of the bioactivity and potential health benefits of peppermint tea (Mentha piperita L.), Phytotherapy Research, v.20, n.8, p.619-33, 2006.

MELLOR, S. Alternatives to antibiotic. Pig Progress, v.16, n.1, p.18-21, 2000.

MELO, E.A.; GUERRA, N.B. Ação antioxidante de compostos fenólicos naturalmente presentes em alimentos. Boletim da Sociedade Brasileira de Ciências e Tecnologias de Alimentos, v.36, n.1, p.1-11, 2002. MOREIRA, A.V.B.; MANCINI-FILHO, J. Influência dos compostos fenólicos de especiarias sobre a lipoperoxidação e o perfil lipídico de ratos. Revista de Nutrição, v.17, n.4, p.411-24, 2004.

NAWAR, W.W. Lipids. In: FENNEMA, O.R. Food Chemistry.
3. ed. New York: Marcel Dekker, 1996. p.225-319.

NGUYEN, D.V. et al. Antioxidative effect of thyme in rapeseed oil. Biology, v.55, n.3, p.277-81, 2000.

NOVAK, J. et al. Ratios of cis- and trans- sabinene hydrate in Origanum marjorana L. and Origanum midrophyllum (Bentham) vogel. Biochemical Systematics and Ecology, v.28, n.7, p.697-704, 2000.

OLSZEWER, E.; FLAM, S.; ELLOVICH, S. Radicais livres em cardiologia - isquemia e reperfusão. São Paulo: Tecnopress, 1997. 156p.

OSAKABE, $N$. et al. Rosmarinic acid, a major polyphenolic component of Perilla frutescens, reduces lipopolysaccharide (LPS)-induced liver injury in dgalactosamine (d-GalN)-sensitized mice. Free Radical Biology \& Medicine, v.33, n.6, p.798-806, 2002.

OSAKABE, N. et al. Rosmarinic acid inhibits epidermal inflammatory responses: anticarcinogenic effect of Perilla frutescens extract in the murine two-stage skin model, Carcinogenesis, n.4, v.25, p.549-57, 2004.

PERRY, E.K. et al. Medicinal plants and Alzheimer's disease: from ethnobotany to phytotherapy, Journal of Pharmacy and Pharmacology, v.51, n.5, p.527-34, 1999. PERRY, N.S.L. et al. Salvia for dementia therapy: review of pharmacological activity and pilot tolerability clinical trial. Pharmacology, Biochemistry and Behaviour, v.75, n.3, p.651-9, 2003.

PHILIPPI, S.T. et al. Pirâmide alimentar adaptada: guia para escolha dos alimentos. Revista de Nutrição, v.12, n.1, p.65-80, 1999.

PIETTA, P.; SIMONETTI, P. MAURI, P. Antioxidant activity of selected medicinal plants. Journal of Agricultural and Food Chemistry, v.46, n.11, p.4487-90, 1998.

PODSEDEK, A. Natural antioxidants capacity of brassica vegetables: a review. Food Science and Technology, v.40, n.1. p.1-11, 2007.

POKORNY, J. Are natural antioxidants better - and safer than synthetic antioxidants? European Journal of Lipid Science and Technology, v.109, n.6, p.629-42, 2007.

POLITEO, O.; JUKIC, M.; MILOS, M. Chemical composition and antioxidant capacity of free volatile aglycones from basil (Ocimum basilicum L.) compared with its essential oil. Food Chemistry, v.101, n.1, p.37985, 2007.

POLYAKOV, N.E. et al. Carotenoids as scavengers of free radicals in a fenton reaction: antioxidants or pro-oxidants? Free Radical Biology \& Medicine, v.31, n.3, p.398-404, 2001.

RAMALHO, V.C.; JORGE, N. Antioxidantes utilizados em óleos, gorduras e alimentos gordurosos. Química Nova, v.29, n.4, p.755-60, 2006a.

RAMALHO, V.C.; JORGE, N. Atividade antioxidante do átocoferol e do extrato de alecrim em óleo de soja purificado. Revista do Instituto Adolfo Lutz, v.65, n.1, p15-20, 2006b.

RIBEIRO, S.M.R. et al. A formação e os efeitos das espécies reativas de oxigênio no meio biológico. Bioscience Journal, v.21, n.3, p.133-149, 2005.

RIBEIRO, S.M.R. et al. Efeitos pró e antioxidantes dosedependente de compostos bioativos. In: COSTA, N.M.B.; ROSA, C.O. (Org.) Alimentos funcionais: benéficos para a saúde. Viçosa: Editora UFV, 2008, p.235-60.

SAGDIÇ, O. Sensitivity of four pathogenic bacteria to Turkish thyme and oregano hydrosols. Lebensmittel

Rev. Bras. PI. Med., Botucatu, v.14, n.2, p.389-399, 2012. 
Wissenschaft und Technologie, v.36, n.5, p.467-73, 2003.

SALEM-JR, N. Introduction to polyunsaturated fatty acids. Backgrounder, v.3, n.1, p.1-8, 1999.

SANCHEZ-MORENO, C. Review: methods used to evaluate the free radical scavenging activity in foods and biological systems. Food Science and Technology International, v.8, n.3, p.121-37, 2002.

SANOCKA, D.; KURPISZ, M. Reactive oxygen species and sperm cells. Reproductive Biology and Endocrinology, v.2, n.1, p.12-8, 2004.

SHAHIDI, F.; JANITHA, P.K.; WANASUNDARA, P.D. Phenolic antioxidants. Critical Reviews in Food Science and Nutrition, v.32, n.1, p.67-103, 1992.

SHYAMALA, B.N. et al. Leafy vegetable extracts antioxidant activity and effect on storage. Innovative Food Science and Emerging Technologies, v.6, n.2, p.23945, 2005.

SILVA, F.A.M.; BORGES, M.F.M.; FERREIRA, M.A. Métodos para avaliação do grau de oxidação lipídica e da capacidade antioxidante. Química Nova, v.22, n.1, p.94103, 1999.

SOARES, S.E. Ácidos fenólicos como antioxidantes. Revista de Nutrição, v.15, n.1, p.71-81, 2002.

TAKEDA, $H$. et al. Rosmarinic acid and caffeic acid produce antidepressive-like effect in the forced swimming test in mice. European Journal of Pharmacology, v.449, n.3, p.261-7, 2002.

TEISSEDRE, P.L.; WATERHOUSE, A.L. Inhibition of oxidation of human low-density lipoproteins by phenolic substances in different essential oils varieties, Journal of Agricultural and Food Chemistry, v.48, n.9, p.3801-5, 2000.

TRONCOSO, N. et al. Fast high performance liquid chromatography and ultraviolet-visible quantification of principal phenolic antioxidants in fresh rosemary. Journal of Chromatography A, v.1100, n.1, p.20-5, 2005.

TSAI, T.H.; TSAI, P.J.; SU, S.C. Antioxidant and antiflammatory activities of several commonly used spices. Journal of Food Science, v.70, n.1, p.93-7, 2005.
ULUBELEN, A. Cardioactive and antibacterial terpenoids from some salvia species. Phytochemistry, v.64, n.2, p.395-9, 2003.

VALENTÃO, P. et al. Antioxidative properties of cardoon (Cynara cardunculus L.) infusion against superoxide radical, hydroxyl radical, and hypochlorous acid. Journal of Agricultural and Food Chemistry, v.50, n.17, p.498993, 2002.

VALKO, M. et al. Free radicals and antioxidants in normal physiological functions and human disease. The International Journal of Biochemistry \& Cell Biology, v.39, n.1, p.44-84, 2007.

VELIOGLU, Y.S. et al. Antioxidant activity and total pheolics in selected fruits, vegetables, and grain products. Journal of Agricultural and Food Chemistry, v.46, n.10, p.41137, 1998.

VIUDA-MARTOS, M. et al. Spices as functional foods. Critical Reviews in Food Science and Nutrition, v.51, n.1, p.13-28, 2011.

WANNISSORN, B. et al. Antibacterial properties of essential oils from Thailandia medicinal plants. Fitoterapia, v.76, n.3, p.233-6, 2005.

WARNER, K. Chemistry of frying oils. In: AKOH, C.C.; MIN, D.B. Food lipids: chemistry, nutrition and biotechnology. 2.ed. New York: Marcel Dekker, 2002. p.205-21.

YANISHLIEVA, N.V.; MARINOVA, E.M. Stabilisation of edible oils with natural antioxidants. European Journal of Lipid Science and Technology, v.103, n.11, p.752-67, 2001. YANISHLIEVA, N.V.; MARINOVA, E.M.; POKORNY, J. Natural antioxidants from herbs and spices. European Journal of Lipid Science and Technology, v.108, n.9, p.776-93, 2006.

YEN, G.; CHEN, H. Antioxidant activity of variuos tea extracts in relation to their antimutagenicity. Journal of Agricultural and Food Chemistry, v.43, n.1, p.27-32, 1995. YILDRIM, A.; MAVI, A.; KARA, A.A. Determination of antioxidant and antimicrobial activities of Rumex crispus L. extracts. Journal of Agricultural and Food Chemistry, v.49, n.8, p.4083-9, 2001. 